\title{
Trichoderma spp. from Pine Bark and Pine Bark Extracts: Potent Biocontrol Agents against Botryosphaeriaceae
}

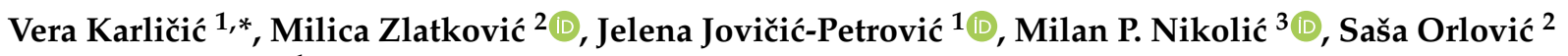 \\ and Vera Raičević ${ }^{1}$ \\ 1 Faculty of Agriculture, University of Belgrade, 11000 Belgrade, Serbia; jelenap@agrif.bg.ac.rs (J.J.-P.); \\ verar@agrif.bg.ac.rs (V.R.) \\ 2 Institute of Lowland Forestry and Environment (ILFE), University of Novi Sad, 21102 Novi Sad, Serbia; \\ milica.zlatkovic@uns.ac.rs (M.Z.); sasao@uns.ac.rs (S.O.) \\ 3 Faculty of Agronomy, University of Kragujevac, 32000 Čačak, Serbia; milanik@kg.ac.rs \\ * Correspondence: vera.karlicic@agrif.bg.ac.rs; Tel.: +381-6428-17485
}

\section{check for}

updates

Citation: Karličić, V.; Zlatković, M. Jovičić-Petrović, J.; Nikolić, M.P.;

Orlović, S.; Raičević, V. Trichoderma spp. from Pine Bark and Pine Bark Extracts: Potent Biocontrol Agents against Botryosphaeriaceae. Forests 2021, 12, 1731. https://doi.org/ $10.3390 / \mathrm{f} 12121731$

Academic Editors: Angela Lo

Monaco, Cate Macinnis-Ng and Om P. Rajora

Received: 29 October 2021

Accepted: 3 December 2021

Published: 9 December 2021

Publisher's Note: MDPI stays neutral with regard to jurisdictional claims in published maps and institutional affiliations.

Copyright: (c) 2021 by the authors. Licensee MDPI, Basel, Switzerland. This article is an open access article distributed under the terms and conditions of the Creative Commons Attribution (CC BY) license (https:// creativecommons.org/licenses/by/ $4.0 /)$.
Abstract: Pinus sylvestris bark represents a rich source of active compounds with antifungal, antibacterial, and antioxidant properties. The current study aimed to evaluate the antifungal potential of P. sylvestris bark against Botryosphaeria dothidea, Dothiorella sarmentorum, and Neofusicoccum parvum (Botryosphaeriaceae) through its chemical (water extracts) and biological (Trichoderma spp. isolated from the bark) components. The water bark extracts were prepared at two temperatures (80 and $120^{\circ} \mathrm{C}$ ) and $\mathrm{pH}$ regimes (7 and 9). The presence of bark extracts (30\%) caused inhibition of mycelial growth of B. dothidea and D. sarmentorum for 39 to $44 \%$ and 53 to $60 \%$, respectively. Moreover, we studied the antagonistic effect of three Trichoderma isolates originating from the pine bark. Trichoderma spp. reduced growth of B. dothidea by $67 \%-85 \%$, D. sarmentorum by $63 \%-75 \%$ and N. parvum by $55 \%-62 \%$. Microscopic examination confirmed typical mycoparasitism manifestations (coiling, parallel growth, hook-like structures). The isolates produced cellulase, $\beta$-glucosidase and $\mathrm{N}$-acetyl- $\beta$-glucosaminidase. The volatile blend detected the emission of several volatile compounds with antimicrobial activity, including nonanoic acid, cubenene, cis- $\alpha$-bergamotene, hexanedioic acid, and verticillol. The present study confirmed in vitro potential of $P$. sylvestris bark extracts and Trichoderma spp. against the Botryosphaeriaceae. The study is an important step towards the use of environmentally friendly methods of Botryosphaeriaceae disease control.

Keywords: Botryosphaeriaceae; biocontrol; pine bark extracts; Trichoderma citrinoviride; VOCs; lytic enzymes

\section{Introduction}

Pesticides are generally considered a quick, easy, and inexpensive solution against plant pathogens. However, constant reliance on chemicals has led to the emergence of more virulent strains with higher resistance to active compounds [1,2]. Understanding the seriousness of this problem has triggered an intense search for alternative solutions, among which "naturally-based" products have attracted special attention. For example, a collaboration between sawmill industries and plant health experts has led to multiple solutions for plant disease control. Sawmill industries generate enormous amounts of bark waste which are mostly burned or disposed to landfills [3,4]. Removed bark represents raw material for substrate formulations, soil conditioners, a variety of human health and industrial products, and bioremediation agents [3,5]. Moreover, it also exhibits antifungal, antibacterial, and insecticidal properties which main carriers are compounds such as terpenes, phenolics, flavonoids, tannins, and pinosylvins [4-6]. In addition, a bark represents a habitat with a complex set of niches available to various microorganisms and communities [7]. Species of the Botryosphaeriaceae (Ascomycota: Botryosphaeriales) are important pathogens of forest, ornamental, fruit trees, and agricultural plants. These fungi are distributed worldwide 
causing a variety of symptoms such as crown die-back, cankers, leaf blights, and shot hole disease [8-11]. The Botryosphaeriaceae are difficult to control as they reside as endophytes and latent pathogens in wood, and the disease symptoms appear when host is under stress [12]. Moreover, these fungi colonize the xylem tissue, and most species are known as generalist pathogens, able to infect different taxonomically unrelated hosts [12-14]. This is of particular concern in urban environments which represent mixtures of native and non-native trees, conifers and broadleaves, and where environmental conditions are such that promote stress on the trees [9].

Fungi of the genus Trichoderma (Ascomycota: Hypocreales: Hypocreaceae) represent a large, ecologically diverse group of well-known biocontrol agents (BCA) [1]. Worldwide, more than $60 \%$ of registered biopesticides are Trichoderma-based [15]. The modes of biocontrol action are various and include competition, mycoparasitism, antibiosis, inactivation of the pathogen's enzymes, and induction of plant disease resistance [2,16]. Moreover, these fungi produce powerful secondary metabolites such as cell-wall degrading enzymes (cellulase, protease, chitinase), volatile organic compounds (VOCs) and non-volatile compounds. Many VOCs have been associated with Trichoderma spp., including sesquiterpenes, alcohols, ketones, lactones, esters, thioalcohols, thioesters, and cyclohexenes [15]. Some VOCs are directly involved in communication of Trichoderma spp. with their co-habitants and in antibiosis [15]. Moreover, the VOCs are usually involved in indirect antagonistic actions, by diffusing and affecting distant opponents [17].

The research of Trichoderma fungi as BCA has been directed towards diseases of agricultural plants and Trichoderma spp. proved to be effective antagonists of numerous pathogens, including Armillaria spp., Botrytis spp., Fusarium spp., Phytophthora spp., Pythium spp., Rhizoctonia spp., Sclerotinia spp., and Verticillium spp. [18,19]. Moreover, pine bark extracts have been shown to inhibit growth of Coniophera puteana (Schumach.) P.Karst., Trametes versicolor (L.ex. Fr.) Pilát, Botrytis cinerea Pers., Colletotrichum acutatum J.H. Simmonds, Phytophthora cactorum (Lebert and Cohn) J. Schröt., and Mycosphaerella fragariae (Tul.) Lindau $[6,20]$. However, the research on Trichoderma spp. as BCA of Botryosphaeriaceae has been limited and mostly focused on grapevine trunk diseases [21]. Moreover, except for a preliminary study [22], there has been no previous research related to pine bark extracts as a biological control option for fungi classified in the Botryosphaeriaceae.

In this regard, the aims of this study were: (1) to conduct in vitro evaluation of the antifungal activity of $P$. sylvestris bark extracts and Trichoderma spp. against Botryosphaeria dothidea (Moug. ex. Fr.) Ces. et de Not., Dothiorella sarmentorum (Fr.) AJL Phillips, A. Alves and J. Luque, and Neofusicoccum parvum (Pennycook and Samuels) Crous, Slippers and AJL Phillips (Ascomycota: Botryosphaeriaceae); (2) to conduct in vitro evaluation of antifungal effects of Trichoderma-VOCs on Botryosphaeriaceae mycelial growth; and (3) to detect effective VOCs and cell-wall degrading enzymes produced by Trichoderma spp. when confronted with the Botryosphaeriaceae.

\section{Materials and Methods}

\subsection{Preparation of Pinus Sylvestris Bark Extracts}

Pinus sylvestris bark extracts were prepared, and extraction yields calculated as described in Karličić et al. [22]. The water extracts were obtained at two temperatures (80 and $120{ }^{\circ} \mathrm{C}$ ) and $\mathrm{pH}$ regimes (7 and 9 ) in three repetitions. The extraction yields represented a percentage of soluble bark powder and were $4 \%$ for extracts prepared at $80{ }^{\circ} \mathrm{C}$ and $5 \%$ for extracts prepared at $120{ }^{\circ} \mathrm{C}$ [22].

\subsection{Fungal Isolates}

Phytopathogenic isolates of B. dothidea (CMW 39314), D. sarmentorum (CMW 39365), and N. parvum (BOT 275) were isolated from Picea abies (L.) H. Karst., Thuja occidentalis L., and Prunus laurocerasus L., respectively. The identity and pathogenicity of the isolates was determined in previous studies $[8,13]$. 
The putative biocontrol fungal agents Trichoderma spp. were isolated from P. sylvestris bark using a serial dilution in a previous study by Karličić et al. [22] and kept in 20\% glycerol at $-80^{\circ} \mathrm{C}$ until use. Morphological identification of the fungal isolates based on colony appearance and microscopic examination (Leica DMLS, Leica Microsystems GmbH, Wetzlar, Germany) was determined after 3-day incubation on PDA at $25^{\circ} \mathrm{C}$ in darkness. Genomic DNA was extracted from five days-old cultures grown on sterile cellophane circles pierced with a sterile hypodermic needle by following the manufacturer's protocol for the ZR Soil Microbe DNA Kit (Zymo Research, Irvine, CA, USA). The ITS region of the rDNA was amplified using primers ITS1F [23] and ITS 4 [24]. Part of the tef 1- $\alpha$ gene and part of the RPB2 gene were amplified using primers EF1 and EF2 and fRPB2-5f and fRPB2-7cr, respectively $[25,26]$. The $25 \mu \mathrm{L}$ PCR reaction mixtures contained $2.5 \mu \mathrm{L}$ of $10 \times$ Taq buffer with $\left(\mathrm{NH}_{4}\right) \mathrm{SO}_{4}$ (Thermo Scientific, Waltham, MA, USA), $3 \mu \mathrm{L}$ of $25 \mathrm{mM}$ $\mathrm{MgCl}_{2}$ (Thermo Scientific, Waltham, MA, USA), $1 \mu \mathrm{L}$ of $100 \mathrm{mM}$ of each dNTPs (Thermo Scientific, Waltham, MA, USA), $0.5 \mu \mathrm{L}$ of $10 \mu \mathrm{M}$ of each primer (Invitrogen, Paisley, UK), $2 \mu \mathrm{L}(40 \mathrm{ng})$ of genomic DNA, $0.3 \mu \mathrm{L}$ (1.5 U) of Taq DNA polymerase (Thermo Scientific, Waltham, MA, USA) and $15.2 \mu \mathrm{L}$ of autoclave-sterilized ultra-pure water The PCR was performed in an Eppendorf Mastercycler epgradient $S$ thermal cycler (Eppendorf AG, Hamburg, Germany) under the conditions described in Kovač et al. [27]. However, the tef $1-\alpha$ region was amplified using annealing temperature of $60^{\circ} \mathrm{C}$ instead of $55^{\circ} \mathrm{C}$.

The PCR products were purified and sequenced by Macrogen Europe (Amsterdam, The Netherlands).

Nucleotide sequences were examined for sequencing errors, edited, and assembled using BioEdit v. 7.2.5, and MEGA X, whereas sequence alignments were carried out using MEGA X and MAFFT v. 7 (on-line) as described in Zlatković et al. [28]. Sequences of the three loci (ITS, tef 1- $\alpha, R P B 2)$ were analysed individually and in combination following the GCPSR concept [29]. The phylogenetic analyses of the individual genes were carried out using Maximum Likelihood (ML) analyses, whereas analyses of the combined datasets (tef $1-\alpha+R P B 2)$, and (ITS + tef $1-\alpha+R P B 2)$ were performed using ML, Maximum parsimony (MP) and Bayesian analyses (BI). The ML and MP analyses were conducted using PhyML v. 3.0 (on-line) and PAUP v. 40b10 as described by Zlatković et al. [8,28]. The BI analyses were carried out in MrBayes v. 3.0b4 as described in Kovač et al. [27]. The DNA sequences generated in this study were deposited in the GenBank genetic sequence database (Table S1 in Supplementary Materials).

\subsection{In Vitro Assessment of Antifungal Activity of Pinus Sylvestris Bark Extracts}

The antifungal activity of $P$. sylvestris bark extracts towards $B$. dothidea, $D$. sarmentorum and N. parvum was assessed, mycelial growth inhibition was calculated and the degree of toxicity was estimated as described in Karličić et al. [22]. The experiment was repeated three times.

\subsection{In Vitro Assay of Trichoderma spp. Antifungal Activity}

The antifungal activity of Trichoderma strains towards B. dothidea, D. sarmentorum and N. parvum was assessed, growth inhibition calculated, and the degree of antagonistic activity estimated as described by Karličić et al. [22]. The experiment was repeated three times. At the same time, microscopic observations of the fungal interactions were performed. Small amounts of mycelia from the plates with individual fungi (negative controls) and from the interaction zones of plates with dual cultures were collected using a sterile hypodermic needle, mounted in distilled water on microscope slides and examined using an Olympus BX53F light microscope (Olympus Co., Tokyo, Japan) with Nomarski differential interference contrast (DIC) equipped with an Olympus SC50 digital camera and accompanying software. 


\subsection{Biochemical Characterization of Trichoderma spp. Antifungal Activity}

The biochemical characterization of Trichoderma spp. antifungal activity included the determination of cell wall-degrading enzymes and the production of siderophores. A semiquantitative determination of cell-wall degrading enzymes (lipase, esterase-lipase, $\mathrm{N}$-acetyl- $\beta$-glucosaminidase and $\beta$-glucosidase) was performed using an API ZYM kit according to the manufacturer's protocol (BioMereux, Craponne, France). The presence of cellulase was determined using carboxymethyl cellulose (CMC) agar method in three repetitions [30]. Siderophore production was detected on the Chrome azurol S (SigmaAldrich, St. Louis, USA) agar medium in three repetitions [31]. The chrome azurol S (CAS) agar plates were inoculated with 5-mm-diameter mycelia discs of three Trichoderma isolates and incubated at $28{ }^{\circ} \mathrm{C}$ for $72 \mathrm{~h}$. The appearance of yellow-orange halo zones around colonies was considered as a positive result.

\subsection{The Effect of Trichoderma VOCs on Mycelial Growth of Botryosphaeriaceae}

The effect of VOCs produced by Trichoderma strains on the mycelial growth of Botryosphaeriaceae was tested using the method of confronted cultures without contacts of the two mycelia [32]. The two Petri dishes containing $20 \mathrm{~mL}$ of potato dextrose agar (PDA, Himedia, India) were individually inoculated with 5-mm-diameter mycelia discs of a pathogen (Botryosphaeriaceae) and an antagonist (Trichoderma spp.). Inoculated plates were sealed with Parafilm ${ }^{\circledR}$, arranged to face each other and incubated at $25^{\circ} \mathrm{C}$ in a microbiological incubator (Binder, Tuttlingen, Germany) in the dark until fungi in the control plates (plates with individual fungi, negative control) reached edges of plates. The experiment was repeated three times. The effects of volatile metabolites were estimated as percentage of mycelial growth inhibition (MGI) calculated using the following equation:

$$
\text { MGI }(\%)=((D C-D T) / D C)) \times 100 \text {, }
$$

where MGI is mycelial growth inhibition, DC is the average diameter of a fungal colony of the control group, and DT is the average diameter of a fungal colony of the treatment group [33].

The antagonistic levels were estimated as described in Ruiz-Gómez et al. [34] and classified as low (MGI 50\%); medium $(50 \%<$ MGI $\leq 60 \%)$; high $(60 \%<$ MGI $\leq 75 \%)$; and very high (MGI > 75\%).

\subsection{Collection of VOCs and GC-MS Analysis}

To determine VOCs emitted by Trichoderma strains penicillin bottles containing $5 \mathrm{ml}$ PDA were inoculated with Trichoderma spp. The VOCs were collected six days after inoculation using headspace solid-phase micro-extraction followed by gas chromatography (Agilent Technologies 7890 B GC System, AIM, Littleton, CO, USA) coupled with mass spectrometry (Agilent Technologies 5977A MSD, AIM, Littleton, CO, USA). Briefly, the $0.2 \mathrm{~g}$ of the sample (PDA + Trichoderma strain) was placed in a headspace vial, followed by the addition of $0.5 \mathrm{~mL}$ of sterilized distilled water. Bottles containing only sterile PDA served as negative controls. Each vial was sealed using a cap with PTFE/silicone septa and incubated at $70{ }^{\circ} \mathrm{C}$. The solid phase microextraction fiber (Polydimethylsiloxane (PDMS) $100 \mu \mathrm{m}$, Agilent Technologies, AIM, Littleton, CO, USA) was inserted into the head space of the vial containing the sample solution. The extraction was carried out at $70^{\circ} \mathrm{C}$ with $90 \mathrm{~min}$ of fiber-exposed time. After sampling, the SPME fiber was withdrawn into the needle, removed from the tube, and inserted into the hot injector port $\left(270^{\circ} \mathrm{C}\right)$ of the GC system where the extracted analyte was desorbed and transferred to the analytical column (HP-5, Agilent Technologies, AIM, Littleton, CO, USA). A relatively long desorption time in the injector (10 $\mathrm{min}$ ) was selected to avoid carryover between runs to ensure full desorption of analyte from the fiber. Ultra-high purity 5.0 grade helium (Messer Tehnogas AD, Belgrade, Serbia) was used as a carrier gas at a flow rate at $1.2 \mathrm{~mL} / \mathrm{min}$ along with the spitless injection. The oven temperature was programmed for an initial $50^{\circ} \mathrm{C}$ for $2 \mathrm{~min}$ and was 
then increased in two steps: $50-80{ }^{\circ} \mathrm{C}$ at a rate of $20^{\circ} \mathrm{C} / \mathrm{min}$ and held for $6 \mathrm{~min}$ at this temperature; $80-280^{\circ} \mathrm{C}$ at a rate of $15^{\circ} \mathrm{C} / \mathrm{min}$ and $240-280{ }^{\circ} \mathrm{C}$ and held for $6 \mathrm{~min}$ at this temperature. During the analysis, data acquisition was carried out in full scan mode $(\mathrm{m} / \mathrm{z}$ 27-350) operated in the electron ionization mode at $70 \mathrm{eV}$ with a source temperature of $230{ }^{\circ} \mathrm{C}$. Volatile compounds were identified by comparison with the National Institute of Standards and Technology (NIST) database. The VOCs that showed mass spectra with match factor $\geq 80 \%$ were considered as identified substances.

\subsection{Statistical Analyses}

The data were subjected to ANOVA followed by Tukey's HSD post-hoc comparison tests to determine if there were statistically significant differences between the means $(p=0.05)$. All statistical analyses were performed using Statistica 12.0 (StatSoft, Tulsa, OK, USA).

\section{Results}

\subsection{In Vitro Assessment of Antifungal Activity of Pinus Sylvestris Bark Extracts}

The antifungal properties of pine bark extracts were tested at two concentrations, i.e., $20 \%$ and $30 \%$ (Table 1 ). The concentration of $20 \%$ inhibited growth of $B$. dothidea for $34 \%-39 \%$ while the concentration of $30 \%$ increased the level of inhibition to $39 \%-44 \%$. The pine bark extracts inhibited D. sarmentorum mycelia for $48 \%-66 \%$. The lowest inhibition $(48 \%)$ was obtained using neutral water extracts prepared at $120{ }^{\circ} \mathrm{C}$, while alkaline water extract prepared at $120^{\circ} \mathrm{C}$ showed the highest inhibition rate $(66 \%)$. Pine bark extracts showed no signs of inhibition of radial growth of N. parvum (Table 1). However, the aerial mycelium of this fungus was sparse compared to the control plate.

Table 1. Mycelial growth inhibition (\%) by pine bark water extracts.

\begin{tabular}{cccccc}
\hline \multicolumn{2}{c}{ Pine Bark Water Extracts } & $\begin{array}{c}\text { Water } \\
\mathbf{p H} / \mathbf{8 0}^{\circ} \mathbf{C}\end{array}$ & $\begin{array}{c}\text { Water } \\
\mathbf{p H} \mathbf{H} / \mathbf{8 0}{ }^{\circ} \mathbf{C}\end{array}$ & $\begin{array}{c}\text { Water } \\
\mathbf{p H 7 / 1 2 0}{ }^{\circ} \mathbf{C}\end{array}$ & $\begin{array}{c}\text { Water } \\
\mathbf{p H} \mathbf{H} / \mathbf{1 2 0}{ }^{\circ} \mathbf{C}\end{array}$ \\
\hline \multirow{3}{*}{ B. dothidea CMW 39314 } & $20 \%$ & $39^{\mathrm{bA}}$ & $36^{\mathrm{abA}}$ & $35^{\mathrm{aA}}$ & $34^{\mathrm{aA}}$ \\
D. sarmentorum CMW & $30 \%$ & $44^{\mathrm{aB}}$ & $43^{\mathrm{aB}}$ & $39^{\mathrm{aB}}$ & $40^{\mathrm{aB}}$ \\
39365 & $20 \%$ & $56^{\mathrm{aA}}$ & $56^{\mathrm{aA}}$ & $48^{\mathrm{aA}}$ & $60^{\mathrm{aA}}$ \\
N. parvum & $30 \%$ & $60^{\mathrm{abA}}$ & $62^{\mathrm{abB}}$ & $53^{\mathrm{aA}}$ & $66^{\mathrm{bA}}$ \\
BOT 275 & $20 \%$ & $\mathrm{NI}$ & $\mathrm{NI}$ & $\mathrm{NI}$ & $\mathrm{NI}$ \\
\hline
\end{tabular}

NI-no inhibition; mean values in the same row with different lowercase letters are significantly different according to the Tukey test $(p=0.05)$; mean values in the same column and same pathogen with different uppercase letters are significantly different according to the Tukey test $(p=0.05)$.

\subsection{Identification of Trichoderma spp.}

Morphology of the three isolates from the P. sylvestris bark was characterized by scarce mycelium producing typical diffusing yellow pigment which was particularly pronounced in isolate T. citrinoviride DEMf TR4. Conidiophores were sparsely branched, representing a long strongly developed central axis from which lageniform and mostly solitary phialides arise, bearing smooth-walled subglobose to ellipsoidal conidia. These morphological features corresponded to common features of the Longibrachiatum section of the genus Trichoderma [35]. Considering the difficulties differentiating Trichoderma species belonging to this section, the additional molecular analyses were performed. Trichoderma spp. were identified using phylogenetic analyses of the ITS $r D N A$, TEF 1- $\alpha$, and RPB2 genes. The concatenated datasets with the two loci (tef $1-\alpha+R P B 2)$ and three loci (ITS + tef $1-\alpha$ $+R P B 2$ ) had 1532 characters of which 577 characters were parsimony informative and 2164 characters of which 623 characters were parsimony informative, respectively. The PHT test showed that the loci can be combined ( $p=0.01$ for both concatenated datasets). The MP analyses of the concatenated dataset of the two loci produced a tree with $\mathrm{CI}=0.6$, $\mathrm{RI}=0.7, \mathrm{TL}=1850$, whereas the analyses of the three loci resulted in two equally most 
parsimonious trees with $\mathrm{CI}=0.6, \mathrm{RI}=0.7, \mathrm{TL}=1948$. The ML, BI and MP analyses of each concatenated dataset yielded trees with the similar topology (Figures 1, S1 and S2).

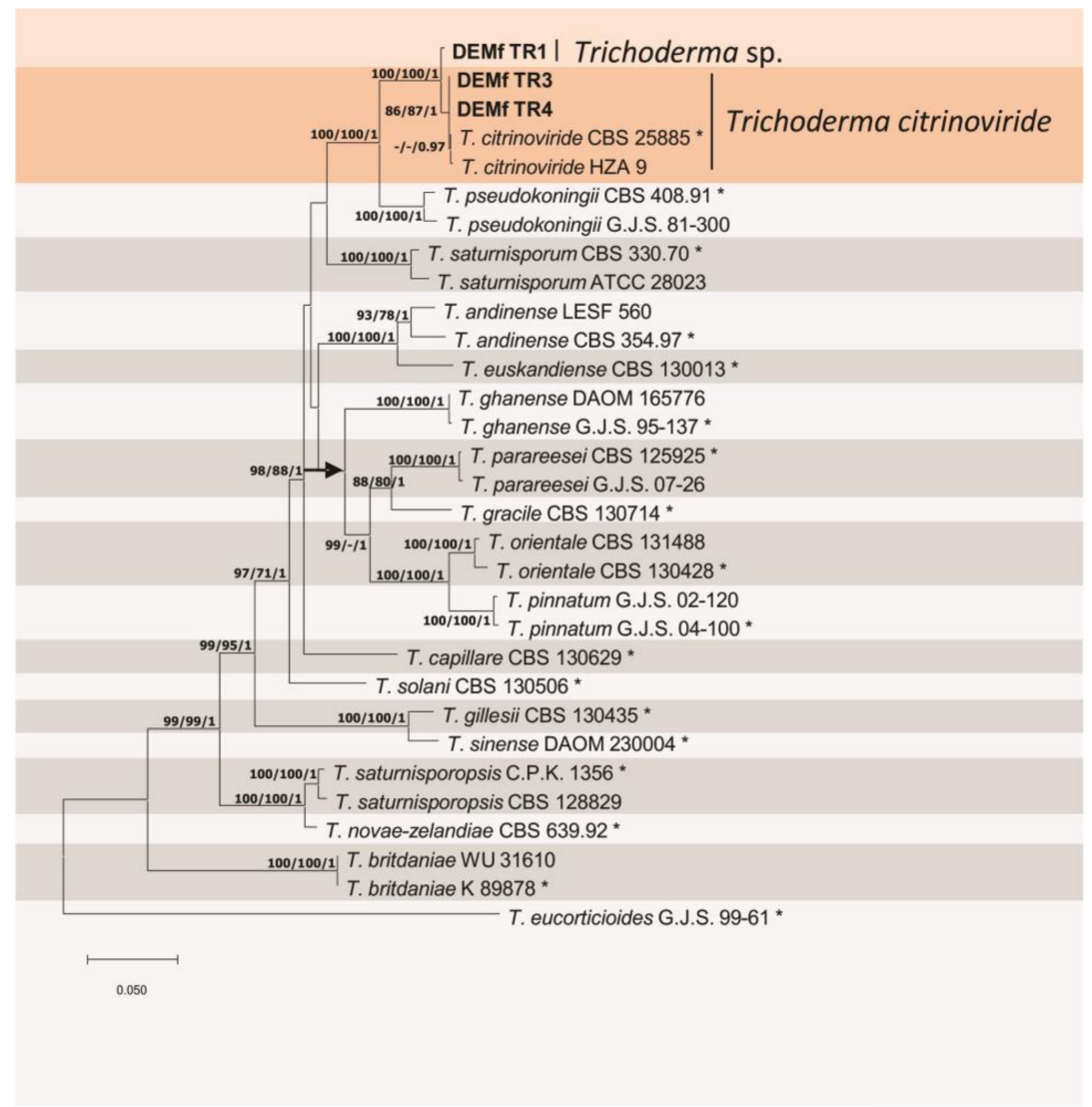

Figure 1. Phylogenetic tree generated from maximum likelihood analysis (ML) based on concatenated alignments of ITS, tef 1- $\alpha$ and RPB2 sequence data showing the position of Trichoderma citrinoviride in relation to its closely related species belonging to the Longibranchiatum clade. ML and maximum parsimony (MP) bootstrap support values greater than $70 \%$ and Bayesian posterior probability values (PP) greater than 0.95 are indicated at the tree nodes (ML/MP/PP). The type strains are marked with an asterisk and isolates sequenced in this study are shown in bold. T. eucorticioides G.J.S. 99-61 (clade Hypocreanum) is included as an outgroup. Scale bar indicates expected number of substitutions per site.

In the phylogenetic analyses of both single and combined loci isolates sequenced in this study clustered within a clade strongly supported in the analyses of the RPB2 gene and fully supported in the analyses of the tef $1-\alpha$ and combined analyses of the two and three loci (Figures 1 and S2). Isolates DEMf TR3 and DEMf TR4 from this study clustered within a sub-clade corresponding to T. citrinoviride (Figures 1 and S2). These isolates had only two single nucleotide polymorphisms (SNPs) that differentiated them from the type strain of T. citrinoviride CBS 25885 (Table S2). The sub-clade corresponding to T. citrinoviride was well-supported in all three analyses $(86 / 87 \%$ ML, MP bootstrap support; posterior probability: 1 ).

Isolate DEMf TR1 clustered within a sub-clade corresponding to T. citrinoviride only in the individual analyses of the ITS and tef 1- $\alpha$ (Figure S1). In analyses of the RPB2, and combined analyses of tef $1-\alpha / R P B 2$ and ITS/tef $1-\alpha / R P B 2$ genes, the isolate clustered within a sister clade to T. citrinoviride (Figures 1 and S2). There were 14 bp differences that differentiated this isolate from the type strain of its phylogenetically closest relative T. citrinoviride (Table S2). Based on phylogenetic analyses, isolates from this study were identified as T. citrinoviride and Trichoderma sp. 


\subsection{In Vitro Assay of Trichoderma spp. Antifungal Activity}

The Trichoderma isolates caused inhibition of Botryosphaeriaceae in confrontation test (Table 2). The highest percentage of $B$. dothidea growth inhibition ( $85 \%$ ) was achieved by T. citrinoviride DEMf TR4, followed by Trichoderma sp. DEMf TR1. This level of antagonistic activity is characterized as very strong. Moreover, T. citrinoviride DEMf TR4 and Trichoderma sp. DEMf TR1 showed very high antagonistic activity towards D. sarmentorum. T. citrinoviride DEMf TR4 was the only Trichoderma isolate to show high antagonistic activity against $N$. parvum.

Table 2. Mycelial growth inhibition (\%) of B. dothidea, D. sarmentorum and N. parvum by Trichoderma spp. isolated from P. sylvestris bark.

\begin{tabular}{cccc}
\hline Pathogen & $\begin{array}{c}\text { Trichoderma sp. } \\
\text { DEMf TR 1 }\end{array}$ & $\begin{array}{c}\text { T. citrinoviride } \\
\text { DEMf TR3 }\end{array}$ & $\begin{array}{c}\text { T. citrinoviride } \\
\text { DEMf TR4 }\end{array}$ \\
\hline B. dothidea CMW 39314 & $76^{\mathrm{ab}}$ & $67^{\mathrm{a}}$ & $85^{\mathrm{b}}$ \\
D. sarmentorum CMW 39365 & $75^{\mathrm{b}}$ & $63^{\mathrm{a}}$ & $75^{\mathrm{b}}$ \\
N. parvum BOT 275 & $59^{\mathrm{b}}$ & $55^{\mathrm{a}}$ & $62^{\mathrm{c}}$ \\
\hline
\end{tabular}

Mean values in the same row with different lowercase letters are significantly different according to Tukey test $(p=0.05)$.

The confrontation test revealed different competition strategies. Interaction of Trichoderma strains with $B$. dothidea and $D$. sarmentorum resulted in overgrowth with replacement [36]. Interaction of Trichoderma strains with N. parvum (Figure 2) was labeled as a deadlock at distance [36] manifested through the presence of an inhibition zone. Moreover, the co-inoculation of these fungi resulted in enhanced production of dark pigmentation in N. parvum.

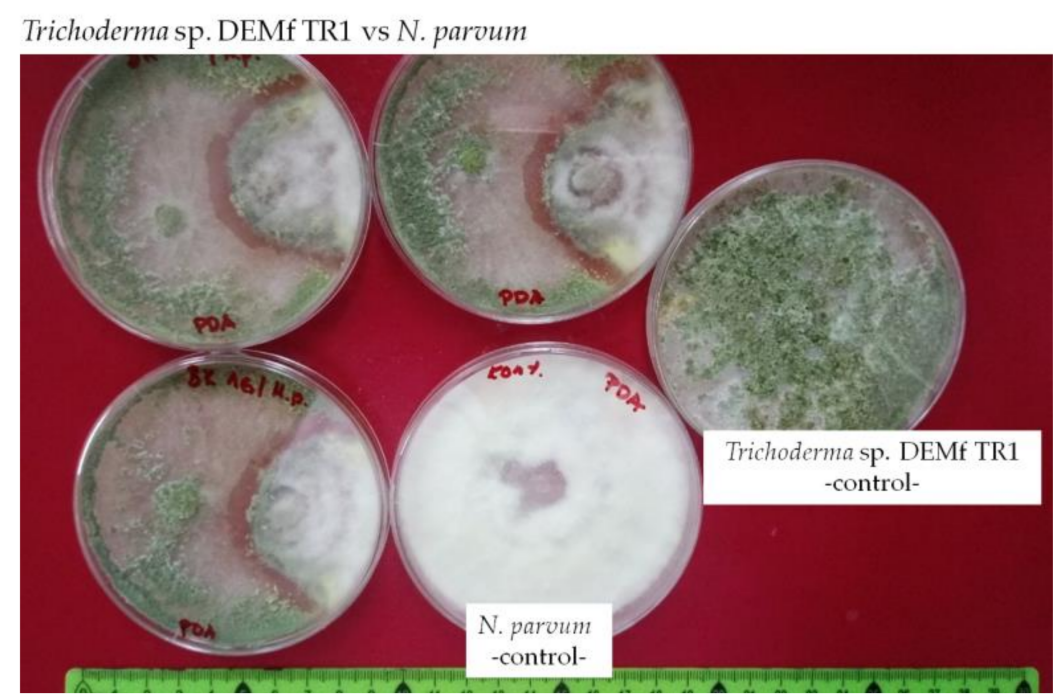

Figure 2. Plate confrontation assay of Trichoderma sp. DEMf TR 1 and Neofusicoccum parvum.

Microscopic observations of the Trichoderma-pathogen meeting zone (Figure 3) revealed different manifestations of BCA action and suggested mycoparasitism as a mode of action. Briefly, the hyphae of Trichoderma sp. DEMf TR1 grew alongside and coiled compactly around the $B$. dothidea hypha. The hook-like structures of Trichoderma spp. were formed around B. dothidea and D. sarmentorum hyphae. Moreover, several other morphological alternations were observed in B. dothidea, D. sarmentorum and N. parvum hyphae, such as vesicle-like structures, vacuolation and cytoplasmatic coagulation as a response to Trichoderma spp. presence. In addition, the micrograph of the meeting zone showed that both Trichoderma spp. and Botryosphaeriaceae isolates, reacted to mutual recognition by 
intensive production of chalmydospores whereas chlamydospores were rarely formed in the control Petri dishes.
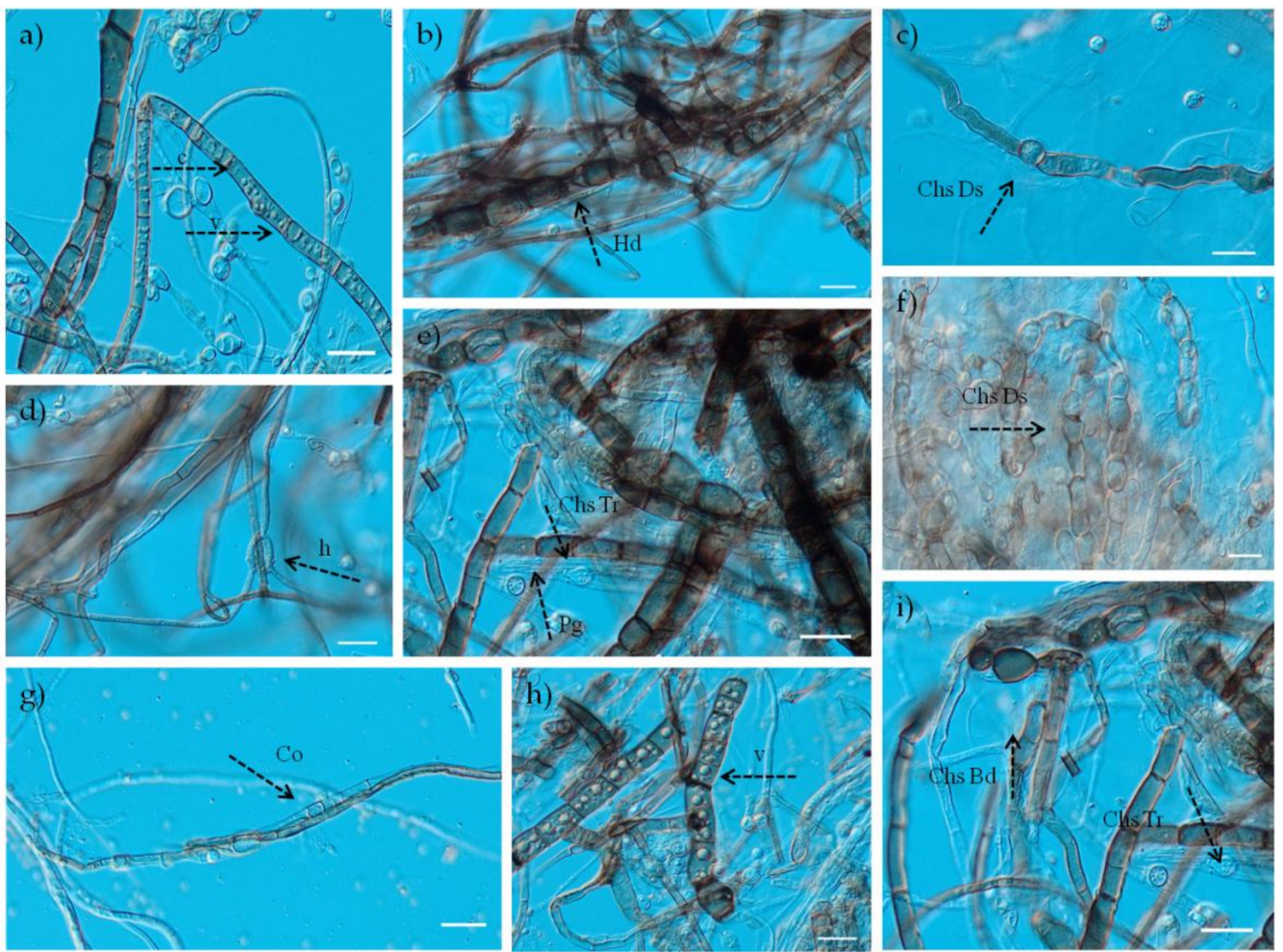

Figure 3. Observations of mycelial interactions between Trichoderma spp. and B. dothidea and D. sarmentorum; (a): c-cytoplasmatic coagulation, v-vacuolation; (b): Hd-hyphal desintegration; (c): Chs Ds—chlamydospores of D. sarmentorum; (d): h-hook-like structures; (e): ChsTrchlamydospores of T. citrinoviride DEMf TR4, Pg—parallel growth; (f): Chs Ds—chlamydospores of D. sarmentorum; (g): Co-coiling; (h): v-vacuolation; (i): Chs Bd-chlamydospores of B. dothidea, ChsTr-chlamydospores of T. citrinoviride DEMf TR4; scale bar $20 \mu \mathrm{m}$.

\subsection{Biochemical Characterization of Trichoderma spp. Antifungal Activity}

Semiquantitative analyses of Trichoderma spp. enzymatic profiles showed the ability of these fungi to produce lipase and esterase-lipase at a moderate level as well as high amounts of $\mathrm{N}$-acetyl- $\beta$-glucosaminidase. T. citrinoviride DEMf TR3 produced high amounts of $\beta$-glucosidase; Trichoderma sp. DEMf TR1 was marked as a moderate producer, while T. citrinoviride DEMf TR4 produced low amounts of the enzyme (Table 3). The three Trichoderma isolates were capable of producing cellulase. The CAS assay confirmed the ability of Trichoderma spp. to produce siderophores.

Table 3. Biochemical characteristics of Trichoderma spp. used in this study.

\begin{tabular}{cccccccc}
\hline \multirow{2}{*}{ Strains } & \multicolumn{5}{c}{ Cell-Wall Degrading Enzymes } & \multirow{2}{*}{ Sid } \\
\cline { 2 - 6 } & Lipase & Est-Lip & Na- $\beta$ & $\beta$-Glu & Cell & \\
\hline Trichoderma sp. DEMf TR 1 & 2 & 2 & 3 & 2 & + & + \\
T. citrinoviride DEMf TR3 & 2 & 2 & 3 & 3 & + & + \\
T. citrinoviride DEMf TR4 & 2 & 2 & 3 & 1 & + & + \\
\hline
\end{tabular}

(est-lip)—esterase-lipase, (Na- $\beta$ )—N-acetyl- $\beta$-glucosaminidase, $(\beta$-glu)— $\beta$-glucosidase, (cell)—cellulase, (sid)— siderophores; 1 -low production, 2-moderate production, and 3-high production according to the API ZYM reading color scale; + positive reaction. 


\subsection{Effect of Trichoderma VOCs on Mycelial Growth of Botryosphaeriaceae}

The VOCs emitted by Trichoderma sp. DEMf TR 1, T. citrinoviride DEMf TR3 and T. citrinoviride DEMf TR4 inhibited mycelial growth of D. sarmentorum for $35 \%, 40 \%$, and $41 \%$, respectively. Moreover, the VOCs induced loss of mycelia pigmentation in B. dothidea (Figure S3). The N. parvum growth was not inhibited. The GC-MS analysis of Trichoderma isolates used in this study confirmed equal profiles of the volatile compounds emitted by Trichoderma sp. DEMf TR1 and T. citrinoviride DEMf TR4. T. citinoviride DEMf TR3 produced six compounds and showed different spectra of VOCs. The exception was trichoacorenol which was produced by all three Trichoderma isolates (Figure 4).

a)

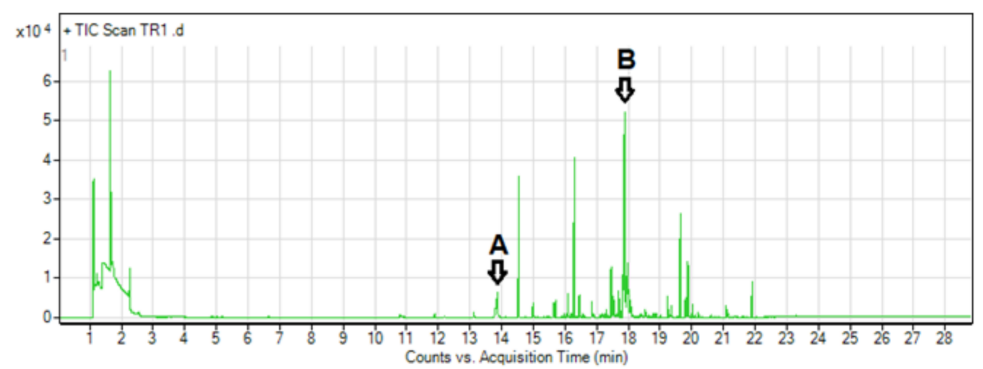

b)

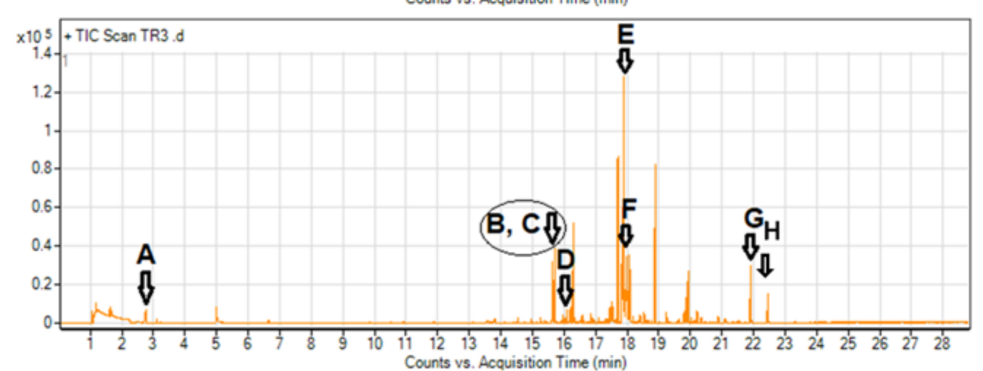

c)

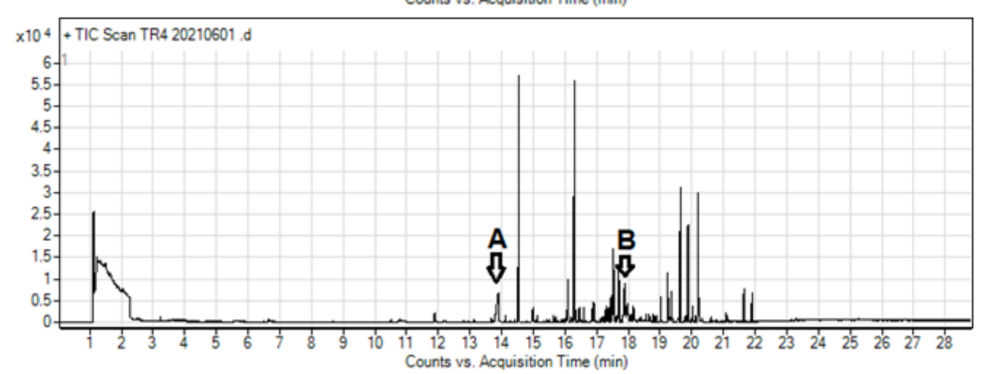

Figure 4. HS-GC-MS profiles of VOCs emitted by Trichoderma isolates: (a) Trichoderma sp. DEMf TR1: A: Nonanoic acid, B: Trichoacorenol; (b) T. citrinoviride DEMf TR3: A: Acetic acid, B: Cubenene, C: Cubenene, D: cis- $\alpha$-bergamotene, E: Trichoacorenol, F: Trichoacorenol, G: Verticillol, H: Hexanedioic acid, bis(2-ethylhexyl) ester; (c) T. citrinoviride DEMf TR4: A: Nonanoic acid, B: Trichoacorenol.

Two compounds were detected in Trichoderma sp. DEMf TR1 and T. citrinoviride DEMf TR4 VOCs spectrum, i.e., trichoacorenol and nonanoic acid. An acetic acid, cubenene, cis- $\alpha-$ bergamotene, trichoacorenol, verticillol, hexanedioic acid, and bis(2-ethylhexyl) ester were detected in T. citrinoviride DEMf TR3 spectrum (Table 4). The amount of trichoacorenol in Trichoderma sp. DEMf TR1 and T. citrinoviride DEMf TR3 was similar and higher compared to the amount of this compund detected in T. citrinoviride DEMf TR4. Nonanoic acid emitted by Trichoderma sp. DEMf TR1 and T. citrinoviride DEMf TR4 were absent in T. citrinoviride DEMf TR3 VOCs profile, but another fatty acid, namely hexanedioic acid, was detected in VOCs spectra of this isolate. Cubenene (syn. naphthalene) was the second most abundant compund in T. citrinoviride DEMf TR3 VOCs blend with 8.25 relative abundance. 
Table 4. VOCs emitted by Trichoderma sp. DEMf TR1, T. citrinoviride DEMf TR3 and T. citrinoviride DEMf TR4 identified by HS-GC-MS.

\begin{tabular}{ccccc}
\hline Isolate & Retention Time(min) & Peak & Volatile Compound & $\begin{array}{c}\text { Relative } \\
\text { Abundance }\end{array}$ \\
\hline Trichoderma sp. & 13.8756 & $\mathrm{~A}$ & Nonanoic acid & 4.84 \\
DEMf TR 1 & 17.8761 & $\mathrm{~B}$ & Trichoacorenol & 17.68 \\
\hline & 2.7580 & $\mathrm{~A}$ & Acetic acid & 1.19 \\
& 15.6375 & $\mathrm{~B}$ & Cubenene & 3.75 \\
T. citrinoviride & 15.7034 & $\mathrm{C}$ & Cubenene & 4.54 \\
DEMf TR3 & 16.2008 & $\mathrm{D}$ & cis- $\alpha$-bergamotene & 0.93 \\
& 17.8873 & $\mathrm{E}$ & Trichoacorenol & 18.88 \\
& 17.9652 & $\mathrm{~F}$ & Trichoacorenol & 1.54 \\
& 21.9053 & $\mathrm{G}$ & Verticillol & 3.43 \\
T. citrinoviride & 22.4483 & $\mathrm{H}$ & Hexanedioic acid & 1.64 \\
DEMf TR4 & 13.9 & $\mathrm{~A}$ & Nonanoic acid & 5.38 \\
\hline
\end{tabular}

\section{Discussion}

The present study showed biocontrol potential of P. sylvestris bark estimated through chemical (water extracts) and biological (T. citrinoviride and Trichoderma sp.) components against three Botryospaheriaceae species, i.e., B. dothidea, D. sarmentorum and N. parvum. The Trichoderma isolates showed the ability to use multiple biocontrol mechanisms and to produce various antifungal substances from cell-wall degrading enzymes, siderophores to VOCs. The VOCs spectra analyses revealed presence of many volatile compounds among which nonanoic acid, cubenene, cis- $\alpha$-bergamotene, hexanedioic acid, and verticillol were previously unknown as T. citrinoviride metabolites.

In this study, P. sylvestris bark extracts showed antifungal effects against $B$. dothidea, $D$. sarmentorum and $N$. parvum. The effects on B. dothidea mycelium growth were characterized as little toxic following the classification of Mori et al. [37]. Moreover, the bark extracts showed moderately toxic effect on $D$. sarmentorum while extracts were non-toxic towards N. paroum. These results are in accordance with the research of Alfredsen et al. [38] who reported slightly toxic effects of Scots pine extracts toward Heterobasidion annosum (Fr.) Bref., Nectria ditissima Tul. and C.Tul., Ceratocystis polonica Siem. (C. Moreau) and moderate level of its toxicity towards Phacidium coniferarum (Hahn) DiCosmo, Nag Raj and W.B. Kendr. Similarly, Vek et al. [39] used 5\% pine bark extracts and reported moderate level of its toxicity towards several fungi, including Schizophyllum commune Fr., Gloeophyllum trabeum (Pers.) Murrill, and Fibroporia vaillantii (DC.) Parmasto. Several studies indicate the high toxicity of the extract to phytopathogens. In a study by Minova et al. [6] pine and spruce bark extracts $(2 \%)$ showed high effectiveness in growth inhibition of several strawberry pathogens, including B. cinerea, C. acutatum, and P. cactorum.

Lomeli-Ramírez et al. [40] reported toxic effects of extracts from P. strobus, P. douglasiana, P. caribea and P. leiophylla toward T. versicolor. Similarly, Maritime pine extracts exhibited a significant antifungal potency against $C$. puteana and T. versicolor which mycelia growth was reduced by $89 \%$ and $87 \%$, respectively [20]. In the study, even though water extracts were prepared on different temperature, duration and $\mathrm{pH}$ regimes, in most cases, the method of preparation did not influence the antifungal effects on $B$. dothidea, D. sarmentorum and N. parvum. However, chemical composition of the extracts was not determined and future work should also include further optimization of the extraction conditions. Nevertheless, this is the first study to show that P. sylvestris bark extracts could serve as biocontrol agents against Botryosphaeriaceae. Further studies should include in planta screening of the bicontrol potential of the extracts. The representatives of Trichoderma gender are well-known as antifungal agents with a long history of usage as BCA against a wide range of pathogens [21]. Several products based on Trichoderma are already used as protectants against grapevine trunk diseases caused by botryosphaeriaceous fungi [21]. 
The assay of Trichoderma spp. antagonistic capabilities toward three representatives of Botryospheriaceae showed that all three isolates obtained from the pine bark are effective in reducing mycelial growth. The antagonistic activity of Trichoderma spp. was marked as high to very high in the case of $B$. dothidea and D. sarmentorum and the isolates inhibited the mycelial growth of the pathogens by up to $85 \%$ and $75 \%$, respectively. The Trichoderma isolates expressed moderate to high antagonistic activity against N. parvum by inhibiting mycelial growth by up to $62 \%$. These results are consistent with several in vitro experiments conducted with botryosphaeriaceous fungi [21,41]. Úrbez-Torres [21] reported high antagonistic activity of T. atroviride who inhibited the growth of Diplodia seriata De Not. by 70\%, and T. koningiopsis who inhibited the growth of N. parvum by 74\%. Mondello et al. [41] reviewed T. atroviride and T. harzianum as highly efficient against D. seriata, Lasiodiplodia theobromae (Pat.) Griffon and Maubl, Neofusicoccum australe Slippers, Crous and M.J. Wingf., N. parvum and T. longibrachiatum as highly efficient against D. seriata. Marraschi et al. [42] reported T. asperelloides, T. asperellum, and T. koningiopsis as antagonists of $L$. theobromae. Moreover, T. citrinoviride expressed high antagonistic activity toward Rhizoctonia solani J.G. Kühn, B. cinerea, Alternaria panax Whetzel, Cylindrocarpon destructans Gerlach and L. Nilsson, P. cactorum and Pythium spp. by inhibiting mycelial growth up to $90 \%$ [43]. Similarly, Kuzmanovska et al. [44] confirmed strong antagonistic properties of T. asperellum and T. harzianum against B. cinerea whose growth was inhibited $77 \%-97 \%$ and $71 \%-94 \%$, respectively.

In vitro confrontations of three Trichoderma isolates and representatives of Botryosphaeriaceae revealed two antagonistic strategies, i.e., overgrowth and production of antifungal compounds. This is in accordance with the work of Kotze et al. [45] who reported formation of inhibition zones between T. atroviride and D. seriata, L. theobromae, and N. australe., and T. atroviride overgrowth of N. parvum. According to Pellan et al. [46] overgrowth of the pathogen suggests stabile interaction of BCA with pathogen metabolism which indicates mycoparasitism as the main mechanism. Moreover, microscopical observations (coiling, parallel growth, hook-like structures) suggested mycoparasitic nature of Trichoderma isolates. Similarly, Kotze et al. [45] reported coiling and hyphal adhesion during interactions of T. atroviride with N. parvum. Moreover, in a study by Park et al. [43] T. citrinoviride showed ability to stick closely and coil around hyphae of $B$. cinerea and $R$. solani. Similar microscopic manifestations of direct mycoparasitism were observed during T. asperellum and T. harzianum confrontation with B. cinerea [44]. Microscopic observations conducted in this study revealed changes in the cytoplasm (coagulation, vacuolation) which are of great importance since they lead to hyphae disintegration and death [47]. According to Krause et al. [36] those changes indicate that antagonistic action is a result of biocontrol mechanisms such as production of antibiotic compounds or competition for nutrients.

In this study, enzymatic profiles of Trichoderma spp. confirmed the ability of these fungi to produce cell-wall degrading enzymes such as esterase-lipase, $N$-acetyl- $\beta$-glucosaminidase, $\beta$-glucosidase, and cellulase. The common constituents of fungal cell-walls are chitin and glucan susceptible to the presence of the extracellular enzymes such as lipases, chitinase, $\mathrm{N}$-acetyl- $\beta$-glucosaminidase, $\beta$-glucosidase and protease $[48,49]$. Trichoderma isolates expressed high production of $\mathrm{N}$-acetyl- $\beta$-glucosaminidase which is already recognized by Lorito et al. [50] as a metabolite of T. harzianum and an effective inhibitor of $B$. cinerea spore germination. Similarly, Park et al. [43] reported a low level of $\beta$-glucosidase activity of T. citrinoviride which is consistent with enzymatic activity of Trichoderma isolates in this study. The three isolates of Trichoderma spp. produced cellulase and this coincides with previous studies which described T. citrinoviride as a producer of strong cellulases [43]. Moreover, Nidhina et al. [48] showed that this enzyme inhibited mycelia growth of Phytophthora spp. Furthermore, Trichoderma isolates from this study expressed another significant biocontrol mechanism, i.e., production of siderophores. This is in accordance with the study of Chen et al. [51] who reported siderophore production by T. citrinoviride and T. atroviride. 
The results of in vitro confrontations from this study conducted to estimate VOCs revealed inhibitory effect of volatile metabolites on growth of D. sarmentorum. Similarly, in the study of Chen et al. [52] T. koningiopsis VOCs showed inhibitory effects on Epicoccum nigrum Link growth. B. dothidea and N. parvum growth was not inhibited and this is in accordance with the study of Stracquadanio et al. [17] who reported the absence of inhibition of Neofusicoccum batangarum Begoude, Jol. Roux and Slippers and N. parvum by T. asperellum and T. atroviride VOCs.

The volatile compounds detected in this study ae already recognized as part of Trichoderma spp. VOCs spectra [1,15]. However this study represents the first report of T. citrinoviride as producer of nonanoic acid, cubenene, cis- $\alpha$-bergamotene, hexanedioic acid, and verticillol. Trichoderma sp. DEMf TR1 and T. citrinoviride DEMf TR4 produced nonanoic acid. Similarly, in a study by Aneja et al. [53] nonanoic acid was detected as part of T. harzianum VOCs spectra and showed inhibitory effects on fungal growth and spore germination of Crinipellis perniciosa Stahel and Moniliophthora roreri Cif. H.C. Evans. However, in this study we focused only on the effect of VOCs on the mycelial growth of Botryosphaeriaceae, and the effect of nonanoic acid on spore germination of these fungi will remain as a task for a future study. Moreover, verticillol was detected in T. citrinoviride DEMf TR3 VOCs spectra. Similarly, in a study of Zhang et al. [19] verticillol was one of the main components of T. harzianum volatile metabolites that caused growth inhibition of Fusarium oxysporum Schlecht. Emend. Snyder and Hansen. T. citrinoviride DEMf TR3 produced cubenene and hexanedioic acid which are an antioxidant and antibacterial compounds $[54,55]$. Considering that trichoacorenol was produced by all three Trichoderma isolates, and that similar levels of $D$. sarmentorum inhibition were observed when co-inoculated with each of the three Trichoderma spp., we hypothesize that trichoacorenol could represent the antifungal component of VOCs. Trichoacorenol together with cis- $\alpha-$ bergamotene belongs to the group of volatile sesquiterpenes with biological potential in suppression of microbial growth [15].

\section{Conclusions}

The present study showed biocontrol potential of P. sylvestris bark through its chemical (water extracts) and biological (Trichoderma spp.) components against three Botryosphaeriaceae species, i.e., B. dothidea, D. sarmentorum and N. parvum.

Trichoderma spp. were capable to activate multiple antifungal mechanisms, from mycoparasitism, production of cell-wall degrading enzymes, competition for nutrients (siderophores) to antifungal volatile metabolites. The study showed the ability of T. citrinoviride to produce nonanoic acid, cubenene, cis- $\alpha$-bergamotene, hexanedioic acid and verticillol, which represent volatile compounds with antimicrobial activity. Moreover, it represents the first report of inhibitory effect of Trichoderma spp. on mycelial growth of D. sarmentorum.

Biological control is an important component of an integrated pathogen management, and this in vitro study is the first and promising step towards the introduction of $P$. sylvestris bark extracts and Trichoderma spp. in biological control programs for landscape pathogens such as Botryosphaeriaceae. Future work should examine the in planta activity of these potential biocontrol agents.

Supplementary Materials: The following are available https:/ / www.mdpi.com/article/10.3390/f1 2121731/s1, Figure S1: Phylogenetic trees generated from Maximum likelihood (ML) analyses based on a single gene alignment of RPB2, tef $1-\alpha$ and ITS sequence data, Figure S2: Phylogenetic tree generated from a maximum likelihood analysis (ML) based on a concatenated alignment of tef 1- $\alpha$ and RPB2 sequence data showing the position of Trichoderma citrinoviride in relation to its closely related species belonging to the Longibranchiatum clade, Figure S3: Effects of VOCs of Trichoderma citrinoviride DEMf TR4 on mycelial growth of D. sarmentorum (a) and B. dothidea (b), Table S1: Sequences used in the phylogenetic analyses, Table S2. Nucleotide differences between Trichoderma sp. and its closest phylogenetic relative T. citrinoviride. 
Author Contributions: Conceptualization, V.K., M.Z. and J.J.-P.; funding acquisition, S.O. and V.R.; methodology, V.K., M.Z., J.J.-P. and M.P.N.; visualization, M.Z. and J.J.-P.; writing-original draft, V.K. and M.Z.; writing—review and editing, V.K., M.Z., J.J.-P., S.O. and V.R. All authors have read and agreed to the published version of the manuscript.

Funding: This research was funded by The Ministry of Education, Science, and Technological Development of the Republic of Serbia, grant number 451-03-9/2021-14/200116 and 451-03-9/2021$14 / 200197$.

\section{Institutional Review Board Statement: Not applicable.}

Informed Consent Statement: Not applicable.

Conflicts of Interest: The authors declare no conflict of interest.

\section{References}

1. Elsherbiny, E.A.; Amin, B.H.; Aleem, B.; Kingsley, K.L.; Bennett, K.K. Trichoderma volatile organic compounds as a biofumigation tool against late blight pathogen Phytophthora infestans in post harvest potato tubers. J. Agric. Food Chem. 2020, 68, 8163-8171. [CrossRef] [PubMed]

2. Aarti, T.; Meenu, S. Role of volatile metabolites from T. citrinoviride in biocontrol of phytopathogens. Int. J. Res. Chem. Environ. 2015, 5, 86-95.

3. Pásztory, Z.; Mohácsiné, I.R.; Gorbacheva, G.; Börcsök, Z. The utilization of tree bark. BioResources 2016, 11, 7859-7888. [CrossRef]

4. Bianchi, S. Extraction and Characterization of Bark Tannins from Domestic Softwood Species. Ph.D. Thesis, University of Hamburg, Hamburg, Germany, 13 January 2017.

5. Fregoso-Madueño, J.N.; Goche-Télles, J.R.; Rutiaga-Quiñones, J.G.; González-Laredo, R.F.; Bocanegra-Salazar, M.; ChávezSimental, J.A. Alternative uses of sawmill industry waste. Rev. Chapingo Ser. Cienc For. Ambient 2017, 23, 243-260. [CrossRef]

6. Minova, S.; Seškēna, R.; Voitkâne, S.; Metla, Z.; Daugavietis, M.; Jankevica, L. Impact of pine (Pinus sylvestris L.) and spruce (Picea abies (L.) Karst.) bark extracts on important strawberry pathogens. Proc. Latv. Acad. Sci. Sect. B Nat. Exact Appl. Sci. 2015, 69, 62-67. [CrossRef]

7. Hagge, J.; Bässler, C.; Gruppe, A.; Hoppe, B.; Kellner, H.; Krah, F.-S.; Müller, J.; Seibold, S.; Stengel, E.; Thorn, S. Bark coverage shifts assembly processesof microbial decomposer communitiesin dead wood. Proc. R. Soc. B 2019, 286, 1-9. [CrossRef] [PubMed]

8. Zlatković, M.; Keča, N.; Wingfield, M.J.; Jami, F.; Slippers, B. Shot hole disease on Prunus laurocerasus caused by Neofusicoccum parvum in Serbia. For. Pathol. 2016, 46, 666-669. [CrossRef]

9. Zlatković, M.; Keča, N.; Wingfield, M.J.; Jami, F.; Slippers, B. Botryosphaeriaceae associated with the die-back of ornamental trees in the Western Balkans. Antonie Leeuwenhoek 2016, 109, 543-564. [CrossRef]

10. Zlatković, M. Botryosphaeriaceae species associated with canker and die-back disease of conifers in urban environments in Serbia. Topola/Poplar. Inst. Lowl. For. Univ. Novi Sad. 2017, 199, 55-75. (In Serbian)

11. Popović, T.; Blagojević, J.; Aleksić, G.; Jelušić, A.; Krnjajić, S.; Milovanović, P. A blight disease on highbush blueberry associated with Macrophomina phaseolina in Serbia. Can. J. Plant Pathol. 2018, 40, 121-127. [CrossRef]

12. Slippers, B.; Wingfield, M.J. Botryosphaeriaceae as endophytes and latent pathogens of woody plants: Diversity, ecology and impact. Fung. Biol. Rev. 2007, 21, 90-106. [CrossRef]

13. Zlatković, M.; Wingfield, M.J.; Jami, F.; Slippers, B. Host specificity of co-infecting Botryosphaeriaceae on ornamental and forest trees in the Western Balkans. For. Pathol. 2018, 48, e12410. [CrossRef]

14. Zlatković, M.; Wingfield, M.J.; Jami, F.; Slippers, B. Genetic uniformity characterizes the invasive spread of Neofusicoccum parvum and Diplodia sapinea in the Western Balkans. For. Pathol. 2019, 49, e12491. [CrossRef]

15. Moya, P.; Girotti, J.R.; Toledo, A.V.; Sisterna, M.N. Antifungal activity of Trichoderma VOCs against Pyrenophora teres, the causal agent of barley net blotch. J. Plant Prot. Res. 2018, 58, 45-53. [CrossRef]

16. Shah, M.M.; Afiya, H. Introductory Chapter: Identification and Isolation of Trichoderma spp.-Their Significance in Agriculture, Human Health, Industrial and Environmental Application. Trichoderma-The Most Widely Used Fungicide; Shah, M.M., Sharif, U., Buhari, T.R., Eds.; IntechOpen: London, UK, 2019; pp. 1-13. [CrossRef]

17. Stracquadanio, C.; Quiles, J.M.; Meca, G.; Cacciola, S.O. Antifungal activity of bioactive metabolites produced by Trichoderma asperellum and Trichoderma atroviride in liquid medium. J. Fungi 2020, 6, 263. [CrossRef] [PubMed]

18. Guo, Y.; Ghirardo, A.; Weber, B.; Schnitzler, J.-P.; Benz, J.P.; Rosenkranz, M. Trichoderma species differ in their volatile profiles and in antagonism toward ectomycorrhiza Laccaria bicolor. Front. Microbiol. 2019, 10, 1-15. [CrossRef]

19. Zhang, F.; Yang, X.; Ran, W.; Shen, Q. Fusarium oxysporum induces the production of proteins and volatile organic compounds by Trichoderma harzianum T-E5. FEMS Microbiol. Lett. 2014, 359, 116-123. [CrossRef] [PubMed]

20. Özgenç, Ö.; Durmaz, S.; Yildiz, Ü.C.; Erişir, E. A comparison between some wood bark extracts: Antifungal activity. Kastamonu Univ. Orman. Derg. 2017, 17, 502-508. [CrossRef]

21. Úrbez-Torres, J.R.; Tomaselli, E.; Pollard-Flamand, J.; Boulé, J.; Gerin, D.; Pollastro, S. Characterization of Trichoderma isolates from southern Italy, and their potential biocontrol activity against grapevine trunk disease fungi. Phytopathol. Mediterr. 2020, 59, 425-439. [CrossRef] 
22. Karličić, V.; Jovičić-Petrović, J.; Marojević, V.; Zlatković, M.; Orlović, S.; Raičević, V. Potential of Trichoderma spp. and Pinus sylvestris bark extracts as biocontrol agents against fungal pathogens residing in the Botryosphaeriales. Environ. Sci. Proc. 2021, 3, 99. [CrossRef]

23. Gardes, M.; Bruns, T.D. ITS primers with enhanced specificity for basidiomycetes-application to the identification of mycorrhizae and rusts. Mol. Ecol. 1993, 2, 113-118. [CrossRef] [PubMed]

24. White, T.J.; Bruns, T.; Lee, S.; Taylor, J.; Innis, M.A.; Gelfand, D.H.; Sninsky, J.J.; White, T.J. Amplification and direct sequencing of fungal ribosomal RNA genes for phylogenetics. In PCR Protocols: A Guide to Methods and Applications; Innis, M.A., Gelfand, D.H., Sninsky, J.J., White, T.J., Eds.; Academic Press: San Diego, CA, USA, 1990; pp. 315-322.

25. O'Donnell, K.; Kistler, H.C.; Cigelnik, E.; Ploetz, R.C. Multiple evolutionary origins of the fungus causing Panama disease of banana: Concordant evidence from nuclear and mitochondrial gene genealogies. Proc. Natl. Acad. Sci. USA 1998, 95, $2044-2049$. [CrossRef] [PubMed]

26. Liu, Y.L.; Whelen, S.; Hall, B.D. Phylogenetic relationships among ascomycetes: Evidence from an RNA polymerase II subunit. Mol. Biol. Evolut. 1999, 16, 1799-1808. [CrossRef] [PubMed]

27. Kovač, M.; Diminić, D.; Orlović, S.; Zlatković, M. Botryosphaeria dothidea and Neofusicoccum yunnanense causing canker and die-back of Sequoiadendron giganteum in Croatia. Forests 2021, 12, 695. [CrossRef]

28. Zlatković, M.; Tenorio-Baigorria, I.; Lakatos, T.; Tóth, T.; Koltay, A.; Pap, P.; Marković, M.; Orlović, S. Bacterial canker disease on Populus x euramericana caused by Lonsdalea populi in Serbia. Forests 2020, 11, 1080. [CrossRef]

29. Taylor, J.W.; Jacobson, D.J.; Kroken, S.; Kasuga, T.; Geiser, D.M.; Hibbett, D.S.; Fisher, M.C. Phylogenetic species recognition and species concepts in fungi. Fungal Genet. Biol. 2000, 31, 21-32. [CrossRef]

30. Romsaiyud, A.; Singkasiri, W.; Nopharatana, A.; Chaiprasert, P. Combination effect of $\mathrm{pH}$ and acetate on enzymatic cellulose hydrolysis. J. Environ. Sci. 2009, 21, 965-970. [CrossRef]

31. Alexander, D.B.; Zuberer, D.A. Use of chrome azurol S reagents to evaluate siderophore production by rhizosphere bacteria. Biol. Fert. Soils 1991, 12, 39-45. [CrossRef]

32. Dennis, C.; Webster, J. Antagonistic properties of species groups of Trichoderma-II. Production of volatile antibiotics. Trans. Br. Mycol Soc. 1971, 57, 47-48. [CrossRef]

33. Mohareb, A.S.; Kherallah, I.E.A.; Badawy, M.E.; Salem, M.Z.M.; Yousef, H.A. Chemical composition and activity of bark and leaf extracts of Pinus halepensis and Olea europaea grown in AL-Jabel AL-Akhdar region, Libya against some plant phytopathogens. J. Appl. Biotechnol. Bioeng. 2017, 3, 331-342. [CrossRef]

34. Ruiz-Gómez, F.J.; Miguel-Rojas, C. Antagonistic potential of native Trichoderma spp. against Phytophthora cinnamomiin the control of Holm Oak decline in Dehesas ecosystems. Forests 2021, 12, 945. [CrossRef]

35. Samuels, G.; Petrini, O.; Kuhls, K.; Lieckfeldt, E.; Kubicek, C.P. The Hypocrea schweinitzii complex and Trichoderma sect. Longibrachiatum. Stud. Mycol. 1998, 41, 1-54.

36. Krause, K.; Jung, E.-M.; Lindner, J.; Hardiman, I.; Poetschner, J.; Madhavan, S.; Mtthäus, C.; Kai, M.; Menezes, R.C.; Popp, J.; et al. Responseof the wood-decay fungus Schizophyllum commune to co-occurring microorganisms. PLoS ONE 2020, 15, e0232145. [CrossRef] [PubMed]

37. Mori, M.; Aoyama, M.; Doi, S.; Kanetoshi, A.; Hayashi, T. Antifungal activity of bark extracts of conifers. Holz Roh Werkst 1995, 53, 81-82. [CrossRef]

38. Alfredsen, G.; Solheim, H.; Slimestad, R. Antifungal effect of bark extracts from some European tree species. Eur. J. Forest Res. 2008, 127, 387-393. [CrossRef]

39. Vek, V.; Poljanšek, I.; Humar, M.; Willför, S.; Oven, P. In vitro inhibition of extractives from knotwood of P. sylvestris (Pinus sylvestris) and black pine (Pinus nigra) on growth of Schizophyllum commune, Trametes versicolor, Gloeophyllum trabeum and Fibroporia vaillantii. Wood Sci. Technol. 2020, 54, 1645-1662. [CrossRef]

40. Lomeli-Ramírez, M.G.; Dávila-Soto, H.; Silva-Guzmán, J.A.; Ruiz, H.G.O.; García-Enriquez, S. Fungitoxic potential of extracts of four Pinus spp. bark to inhibit fungus Trametes versicolor (L.ex. Fr.) Pilát. BioResources 2016, 11, 10575-10584. [CrossRef]

41. Mondello, V.; Songy, A.; Battiston, E.; Pinto, C.; Coppin, C.; Trotel-Aziz, P.; Clément, C.; Mugnai, L.; Fontaine, F. Grapevine trunk diseases: A review of fifteen years of trials for their control with chemicals and biocontrol agents. Plant Dis. 2018, 102, 1189-1217. [CrossRef] [PubMed]

42. Marraschi, R.; Ferreira, A.B.M.; da Silva Bueno, R.N.; Leite, J.A.B.P.; Lucon, C.M.M.; Harakava, R.; Leite, L.G.; Padovani, C.R.; Bueno, C.J. A protocol for selection of Trichoderma spp. to protect grapevine pruning wounds against Lasiodiplodia theobromae. Braz. J. Microbiol. 2019, 50, 213-221. [CrossRef]

43. Park, Y.-H.; Mishra, R.C.; Yoon, S.; Kim, H.; Park, C.; Seo, S.-T.; Bae, H. Endophytic Trichoderma citrinoviride isolated from mountain-cultivated ginseng (Panax ginseng) has great potential as a biocontrol agent against ginseng pathogens. J. Ginseng Res. 2019, 43, 408-420. [CrossRef] [PubMed]

44. Kuzmanovska, B.; Rusevski, R.; Jankulovska, M.; Oreshkovikj, K.B. Antagonistic activity of Trichoderma asperellum and Trichoderma harzianum against genetically diverse Botrytis cinerea isolates. Chil. J. Agric. Res. 2018, 78, 391-399. [CrossRef]

45. Kotze, C.; Van Niekerk, J.; Mostert, L.; Halleen, F.; Fourie, P. Evaluation of biocontrol agents for grapevine pruning wound protection against trunk pathogen infection. Phytopathol. Mediterr. 2011, 50, S247-S263. 
46. Pellan, L.; Durand, N.; Martinez, V.; Fontana, A.; Schorr-Galindo, S.; Strub, C. Commercial biocontrol agents reveal contrasting comportments against two mycotoxigenic fungi in cereals: Fusarium graminearum and Fusarium verticillioides. Toxins 2020, $12,152$. [CrossRef] [PubMed]

47. Maheshwari, D.K.; Dubey, R.C.; Sharma, V.K. Biocontrol effects of Trichoderma virens on Macrophomina phaseolina causing charcoal rot of peanut. Ind. J. Microbiol. 2001, 41, 251-256.

48. Nidhina, K.; Sharadraj, K.M.; Prathibha, V.H.; Hegde, V.; Gangaraj, K.P. Antagonistic activity of Trichoderma spp. to Phytophthora infecting plantation crops and its beneficial effect on germination and plant growth promotion. Vegetos 2016, 29, 19-26. [CrossRef]

49. Danilović, G.; Radić, D.; Raičević, V.; Jovanović, L.J.; Kredics, L.; Panković, D. Extracellular enzyme activity of Trichoderma strains isolated from different soil types. In Proceedings of the 2nd International Symposium for Agriculture and Food, Ohrid, North Macedonia, 7-9 October 2015.

50. Lorito, M.; Hayes, C.K.; Di Pietro, A.; Woo, S.L.; Harman, G.E. Prification, characterization, andsynergistic activity of glucan 1,3- $\beta$-glucosidse and an N-cetyl- $\beta$-glucosaminidase from Trichoderma harzianum. Mol. Plant Pathol. 1994, 84, 398-405.

51. Chen, D.; Hou, Q.; Jia, L.; Sun, K. Combined use of two Trichoderma strains to promote growth of pakchoi (Brassica chinensis L.). Agronomy 2021, 11, 726. [CrossRef]

52. Chen, J.-L.; Liu, K.; Miao, C.-P.; Sun, S.-Z.; Chen, Y.-W.; Xu, L.-H.; Guan, H.-L.; Zhao, L.-X. Salt tolerance of endophytic Trichoderma koningiopsis YIM PH30002 and its volatile organic compounds (VOCs) allelopathicactivity against phytopathogens associated with Panax notoginseng. Ann. Microbiol. 2016, 66, 981-990. [CrossRef]

53. Aneja, M.; Gianfagna, T.J.; Hebbar, P.K. Trichoderma harzianum produces nonanoic acid, an inhibitor of spore germination and mycelial growth of two cacao pathogens. Physiol. Mol. Plant Pathol. 2005, 67, 304-307. [CrossRef]

54. Shareef, H.K.; Muhammed, H.J.; Hussein, H.M.; Hameed, I.H. Antibacterial effect of ginger (Zingiber officinale) roscoe and bioactive chemical analysis using Gas chromatography mass spectrum. Orient. J. Chem. 2016, 32, 817-837. [CrossRef]

55. Kim, J.-E.; Seo, J.-H.; Bae, M.-S.; Bae, C.-S.; Yoo, J.-C.; Bang, M.-A.; Cho, S.-S.; Park, D.-H. Antimicrobial constituents from Allium hookeri Root. Nat. Prod. Commun. 2016, 11, 237-238. [CrossRef] 